\title{
TcNPR3 from Theobroma cacao functions as a repressor of the pathogen defense response
}

\author{
Zi Shi ${ }^{1}$, Yufan Zhang ${ }^{1}$, Siela N Maximova ${ }^{2}$ and Mark J Guiltinan ${ }^{1,2,3^{*}}$
}

\begin{abstract}
Background: Arabidopsis thaliana (Arabidopsis) NON-EXPRESSOR OF PR1 (NPR1) is a transcription coactivator that plays a central role in regulating the transcriptional response to plant pathogens. Developing flowers of homozygous npr3 mutants are dramatically more resistant to infection by the pathogenic bacterium Pseudomonas syringae, suggesting a role of NPR3 as a repressor of NPR1-mediated defense response with a novel role in flower development.

Results: We report here the characterization of a putative NPR3 gene from the tropical tree species Theobroma cacao (TCNPR3). Like in Arabidopsis, TcNPR3 was constitutively expressed across a wide range of tissue types and developmental stages but with some differences in relative levels compared to Arabidopsis. To test the function of TCNPR3, we performed transgenic complementation analysis by introducing a constitutively expressing putative TCNPR3 transgene into an Arabidopsis npr3 mutant. TCNPR3 expressing Arabidopsis plants were partially restored to the WT pathogen phenotype (immature flowers susceptible to bacterial infection). To test TCNPR3 function directly in cacao tissues, a synthetic microRNA targeting TcNPR3 mRNA was transiently expressed in cacao leaves using an Agrobacterium-infiltration method. TCNPR3 knock down leaf tissues were dramatically more resistance to infection with Phytophthora capsici in a leaf bioassay, showing smaller lesion sizes and reduced pathogen replication.

Conclusions: We conclude that TCNPR3 functions similar to the Arabidopsis NPR3 gene in the regulation of the cacao defense response. Since TcNPR3 did not show a perfect complementation of the Arabidopsis NPR3 mutation, the possibility remains that other functions of TCNPR3 remain to be found. This novel knowledge can contribute to the breeding of resistant cacao varieties against pathogens through molecular markers based approaches or biotechnological strategies.
\end{abstract}

Keywords: Plant defense, NPR3, Negative regulator, Cacao, NPR1

\section{Background}

To effectively combat a wide range of pathogens, plants are able to induce a complex network of defense responses against invasions [1]. Upon activation of the defense response, a large shift in resource allocation results in reduced growth rate and seed production $[2,3]$. Therefore, defense responses are highly regulated through a complicated network of positive and negative regulatory mechanisms that allow plants to react appropriately to pathogens only when needed [4-6].

\footnotetext{
* Correspondence: mjg9@psu.edu

${ }^{1}$ The Huck Institutes of the Life Sciences, The Pennsylvania State University,

University Park, PA 16802, USA

${ }^{2}$ The Department of Plant Science, The Pennsylvania State University,

University Park, PA 16802, USA

Full list of author information is available at the end of the article
}

The most well-studied regulator of systemic acquired pathogen resistance (SAR) is Non Expressor of PR1 (NPR1), a transcription coactivator that regulates $P R$ gene expression in the SA-dependent signaling pathway $[7,8]$. Arabidopsis thaliana (Arabidopsis) npr1 mutants exhibit higher susceptibility to pathogen infection and impaired expression of $P R$ genes [9]. Additional positive regulators have been identified in SA-dependent systemic signaling, including Enhanced Disease susceptibility 1 (EDS1) [10], SA Induction Deficient 1 (SID1) [11] and TGA transcription factors [12].

Several negative regulators of the plant defense response have also been discovered in Arabidopsis [13-18]. The NIMIN proteins show no obvious homology to known transcription factors other than a short EAR motif, a motif found on repressors of ethylene and auxin induced transcription. NIMIN is thought to act as a modulator of PR-1

\section{() Biomed Central}

(c) 2013 Shi et al.; licensee BioMed Central Ltd. This is an open access article distributed under the terms of the Creative Commons Attribution License (http://creativecommons.org/licenses/by/2.0), which permits unrestricted use, distribution, and reproduction in any medium, provided the original work is properly cited. 
transcription levels, suppressing its expression during SA stimulated induction. The cpr1 (constitutive expresser of PR1) mutation causes constitutively high SA levels, increased PR1 expression in the absence of pathogen, and thus enhanced disease resistance [16]. SNI1 (suppressor of npr1-1 inducible) was identified as a repressor of genes targeted by NPR1 induction, thus dampening the basal expression levels of downstream PR genes $[13,19]$. SNI1 is a nuclear protein and it may function via chromatin remodeling through histone modification. Moreover, the WRKY transcription factors WRKY11 and WRKY17 are also involved in negative regulation of defense responses [15]. NPR1 was recently shown to bind to SA and this interaction results in a conformational change which may contribute to the ability of NPR1 to activate transcription [20].

The functions of the Arabidopsis NPR1 paralogs, NPR2, NPR3 and NPR4, are partially known. Various lines of evidence demonstrate that they all act as components of the SA signal transduction pathway [21-24]. NPR3 and NPR4 have both been shown to bind to SA and to function in the regulation of the rate of proteosomal degradation of NPR1 through a Cullin 3/ubiquitinE3 ligase mediated degradation pathway, thus linking SA concentration to the NPR1-SA-dependant transcriptional defense response [24]. NPR3 acts as a repressor of NPR1 function by enhancing NPR1 degradation, while NPR4 acts at lower SA concentrations to enhance NPR1 stability and increasing defense pathway activation. It is possible that all three proteins act as SA receptors working in different mechanisms to co-regulate the transcriptional defense response.

Understanding the mechanisms regulating the defense response has profound implications for agriculture. Such knowledge can be used to design breeding strategies, or to create transgenic plants with enhanced disease resistance against the plethora of plant pathogens. One such disease, witches' broom disease of Theobroma cacao (cacao), is caused by the fungal pathogen Moniliophthora perniciosa, is a serious disease in Latin America. Indigenous to the Amazon rainforest, it now occurs in most cocoa growing regions in South America and has became a serious threat to world cocoa production $[25,26]$. Terminal and axillary buds, flower cushions and developing pods are highly susceptible to witches' broom infection, resulting in severe yield loss [27]. The genome of this pathogen was recently sequenced [28] and a deeper understanding of the mechanisms of pathogenicity is beginning to emerge [29-32]. In an effort to advance breeding of disease resistant varieties of cacao, we conducted research to further our understanding of the defense response in this tropical tree species.

Several homologs of Arabidopsis defensive proteins were previously identified in cacao after SA/MeJA treatment $[33,34]$ suggesting that a translational biology approach could be used to accelerate our knowledge of the cacao defense pathways. We have previously described the isolation and functional analysis of the cacao TcNPR1 gene [35] and demonstrated it is a functional ortholog of Arabidopsis NPR1 by restoring the npr1-2 mutant phenotype in transgenic Arabidopsis. In addition, a phylogenetic analysis of all four of the NPR1-like gene family members in cacao was presented in the supplementary material of Agrout et al. [36], in which the full genome sequence of Theobroma cacao was described.

In this manuscript, we present the isolation and functional analysis of the Theobroma cacao gene Tc06t011480 (TcNPR3) that is homologous to the Arabidopsis NPR3 gene At1G5G45110. The TcNPR3 gene was capable of partial restoration of the Arabidopsis npr3-3 mutant disease resistant flower phenotype. Moreover, micro-RNAmediated knock down of TcNPR3 expression in cacao leaves was strongly correlated to decreased susceptibility to infection by the cacao pathogen Phytophthora capsici. Based on our results, we conclude that TcNPR3 shares at least some of the central features of Arabidopsis NPR3, and plays a role as a negative regulator of the defense response.

\section{Material and methods}

\section{Genomic resources utilized}

Cacao transcriptomes: The Esttik database (http://esttik. cirad.fr/) houses EST discovery data from fifty-six different cDNA libraries constructed from different organs, genotypes and in varying environmental conditions [37]. 454 transcriptome: A cDNA library from six mixed tissues of Criollo genotype (B97-61/B2) was sequenced by Roche/ 454 technology as previously described [36]. Cacao genome sequence: The genome of Theobroma cacao was sequenced and analyzed from a Belizean Criollo genotype (B97-61/B2) and can be accessed via the Gbrowse website (http://cocoagendb.cirad.fr) [36].

\section{Full length CDNA cloning and genomic DNA cloning of TCNPR3}

Unless otherwise indicated, all chemicals and supplies were obtained from Sigma-Aldrich, St. Louis, MO. A partial sequence of the TcNPR3 gene was identified by screening BAC filter arrays constructed using genomic DNA of genotype LCT-EEN 37 obtained from the Clemson University Genomic Institute (http://www.genome.clemson.edu/) using a partial TcNPR1 sequence as a radio-labeled hybridization probe. Based on its partial sequence, primers were designed to clone the full-length cDNA of TcNPR3 from genotype Scavina6 (SCA6). Total RNA was isolated from cacao SCA6 stage $C$ leaves as previously described in [33]. Cacao cDNA was synthesized in a final volume of $25 \mu \mathrm{l}$ from $2 \mu \mathrm{g}$ of total cacao RNA using M-MLV reverse transcriptase (New England Biolabs, Inc., 
Ipswich, MA) as described previously [35]. A full-length TcNPR3 cDNA (starting at the ATG codon and ending at the stop codon of the predicted CDS) was cloned by PCR using $1 \mu \mathrm{l}$ of $1 / 2$ diluted cDNA as template and $5 \mu \mathrm{M}$ of primers were used to include $K p n \mathrm{I}$ and $N o t \mathrm{I}$ restriction sites at the $5^{\prime}$ - and $3^{\prime}$-ends respectively (TcNPR3-5'-KpnI, GCGGTACCATGGCGTATTTATCTGAG; TcNPR3-3' NotI, GCGCGGCCGCTCACAATTTTCTGAGC). All synthetic oligonucleotides were purchased from Integrated DNA Technologies, Coralville, ID. PCR was performed using the following conditions: $94^{\circ} \mathrm{C}$ for $2 \mathrm{~min}$., 32 cycles of $94^{\circ} \mathrm{C}$ for $30 \mathrm{sec}$., $60^{\circ} \mathrm{C}$ for $30 \mathrm{sec}$., followed by a $5 \mathrm{~min}$. final extension at $72^{\circ} \mathrm{C}$. PCR product was resolved on $1 \%$ agarose gels, purified with the GENECLEAN II Kit (Q-Biogene Inc., Solon $\mathrm{OH}$ ) and cloned into the pGEM T-Easy vector (Promega Corporation, Madison WI). Forward and reverse sequencing was performed at the Penn State Genomics Core Facility to verify the sequence. The resulting clone was designated as pGEM-TcNPR3. The full-length TcNPR3 cDNA sequence was used to identify the TcNPR3 genomic locus in the genome assembly (Tc06t011480) using blastn [38].

\section{Gene and protein structure and analysis}

The TcNPR3 gene structure was annotated by alignment of the full-length cDNA with the genomic sequence using SPIDEY (http://www.ncbi.nlm.nih.gov/spidey/). Arabidopsis NPR3 protein sequence was retrieved from TAIR (At5g45110) and compared to the conceptual translation of the TcNPR3 sequence using MUSCLE [39]. Putative functional motifs were identified using Simple Modular Architecture Research Tool (SMART) (http://smart.embl-heidelberg.de/).

\section{Gene expression measurements}

RT-Q-PCR was performed to measure the relative expression of TcNPR3 in different cacao tissues. Basically, total RNA was extracted from leaf stages $\mathrm{A}, \mathrm{C}$ and $\mathrm{E}$, open flowers, un-open flowers, roots, pod seeds and pod exocarps. Three biological replicates were collected for each tissue. Cacao cDNA was synthesized in a final volume of $25 \mu \mathrm{l}$ from $2 \mu \mathrm{g}$ of total cacao RNA using M-MLV reverse transcriptase (New England Biolabs, Inc., Ipswich, MA) following the protocol given in [35].

The primers to detect TcNPR3 transcripts were designed based on the coding sequence of TcNPR3 (TcNPR3Realtime-5': GCCAGAGGTTGACAAGACCAAAGG; TcNPR3-Realtime-3': GTCTCATGTGTAGATCATCAG CCAACG). The $10 \mu \mathrm{l}$ quantitative RT-Q-PCR mixture contains $4 \mu$ liluted-cDNA (1:50), $5 \mu$ l SYBR Green PCR Master Mix (Takara), $0.2 \mu \mathrm{l}$ Rox, and $0.4 \mu \mathrm{l}$ each $5 \mu \mathrm{M}$ primers. Each reaction was performed in duplicates in Roche Applied Biosystem StepOne Plus Realtime PCR System under the following program: $15 \mathrm{~min}$ at $94^{\circ} \mathrm{C}$,
40 cycle of 15 sec. at $94^{\circ} \mathrm{C}, 20 \mathrm{sec}$. at $60^{\circ} \mathrm{C}$, and $40 \mathrm{sec}$. at $72^{\circ} \mathrm{C}$. The specificity of the primer pairs were examined by RT-Q-PCR visualized on the 2\% Agarose Gel and dissociation curve. Based on consistent expression level in the different samples, the cacao tubulin1 (TUB1, Tc06g000360) gene was used as a control and used to normalize expression data (TUB1-5': GGAGGAGTC TCTATAAGCTTGCAGTTGG and TUB1-3': ACATAAGCATAGCCAGCTAGAGCCAG).

\section{Transgenic Arabidopsis genetic complementation}

A T-DNA binary vector designed for overexpression of the TcNPR3 coding sequence (p35S: TcNPR3) was created as follows. The TcNPR3 coding sequence was excised from pGEM-TcNPR3 vector and cloned into $K p n \mathrm{I}$ and NotI sites of an intermediate cloning vector (pE2113) between the very strong E12- $\Omega$ promoter [40] and a $35 \mathrm{~S}-\mathrm{CaMV}$ terminator. A $3 \mathrm{~kb}$ restriction fragment containing this TcNPR3 gene cassette was excised from pE2113 using $E c o R I$ and $P v u I I$ and ligated into the EcoRI and SmaI sites of pCAMBIA-1300 [41]. Ligations were performed for 1 hour at room temperature with 3 units of T4 DNA ligase (Promega Corporation, Madison WI) resulting in p35S:TcNPR3. The binary vector p35S:TcNPR3 containing a plant selectable hygromycin resistance gene was introduced into Agrobacterium tumefaciens strain AGL1 by electroporation as previously described [42]. The floral dip method was used to transform Arabidopsis npr3-3 mutants with p35S:TcNPR3 [43]. Seeds were collected for 5 individual transgenic lines and the screening of positive transformants was conducted as in [35]. Flower tissues from six-week old soil-grown Col-0, npr3-3 mutant and five individual transgenic lines were collected. RNA was extracted from each genotype using RNeasy plant mini kit (QIAGEN, Valencia CA). cDNA was synthesized using M-MLV reverse transcriptase (New England Biolabs, Inc., Ipswich, MA) as in [35]. RT-PCR was performed to identify the heterologous TcNPR3 expression. AtUbiquitin served as a cDNA loading and normalization control. Following primers and conditions were employed: TcNPR3RT5': TGCTTGTCGACCCGCCATCAATTT; TcNPR3RT3': AGGTTGTCTCAGCATGTGCTATGTCC (27 cycles of $94 \mathrm{C}$ for $30 \mathrm{sec}, 56^{\circ} \mathrm{C}$ for $30 \mathrm{sec}$, $72^{\circ} \mathrm{C}$ for $1 \mathrm{~min})$. Ubiquitin-5': ACCGGCAAGACCATCACTCT; Ubiquitin-3': AGGCCTCAACTGGTTGCTGT (22 cycles of $94^{\circ} \mathrm{C}$ for 30 sec., $54^{\circ} \mathrm{C}$ for 30 sec., $72^{\circ} \mathrm{C}$ for $1 \mathrm{~min})$. The PCR products were resolved on $1 \%$ agarose gels.

\section{Pseudomonas syringae infection assay}

Plants were grown in a Conviron growth chamber at $22^{\circ} \mathrm{C}$, with $16 \mathrm{~h}$ light $/ 8 \mathrm{~h}$ dark cycle $60 \%$ humidity and $200 \mu \mathrm{M} /$ $\mathrm{m}^{2}$ light intensity (Octron $4100 \mathrm{~K}$ Ecologic bulbs). Pseudomonas syringae pv. tomato DC3000 cultures were grown 
on pseudomonas agar with kanamycin $(25 \mathrm{ng} / \mu \mathrm{l})$ and rifampicin $(100 \mathrm{ng} / \mu \mathrm{l})$ at $28^{\circ} \mathrm{C}$ for two days. The pathogen infection and bacterial bioassay was conducted as previously described in [23].

\section{Cacao microRNA construct}

A 21 nucleotide microRNA of TcNPR3 was designed using the web-based designer at WMD3 (http://wmd3.weigel world.org/cgi-bin/webapp.cgi?page $=$ Designer;project $=$ stdwmd) by choosing cacao EST TcaGI-3.0 database. The miRNA targets $373 \mathrm{bp}$ upstream of the stop codon. The primer sequences were: (capital letters indicates the target sequence of TcNPR3).

I miR-s gaTTTGAACCTTTTGATGCACA Atctctcttttgtattcc

II miR-a gaTTGTGCATCAAAAGGTTCAAAtcaaa gagaatcaatga

III miR*s gaTTATGCATCAAAACGTTCAATtca caggtcgtgatatg

IV miR*a gaATTGAACGTTTTGATGCATAAtcta catatatattcct

A sequence containing an inverted repeat/hairpin loop structure was amplified from pRS300 following the protocol on WMD3 (Stephan Ossowski, Joffrey Fitz, Rebecca Schwab, Markus Riester and Detlef Weigel, personal communication), also as described in [44,45], with the exception of using the following primers: F-SpeI: TACTAGTGGTACCGGGCCCCCC and R-HpaI: GCGT TAACCTAGTGGATCCCCCCATGG instead of oligo A and $B$, respectively which were used to amplify the completed fragment for cloning into the SpeI/HapI sites of transformation vector pGH00.0126 [46] driven by the $35 \mathrm{~S}$ promoter.

\section{Transient gene knockout and detached leaf pathogen bioassay}

Vectors pGH00.0126 (control) and pGS12.0225 (including gene cassette 35S: TcNPR3 microRNA) were transformed in cacao leaves by Agrobacterium (AGLI strain) vacuum infiltration. Agrobacterium was grown in 523 medium overnight to $\mathrm{OD}_{600}=1.0$ and induced as described in Maximova et al., [47] for 5 hours. Leaves, at developmental stage C [35], were collected from greenhouse-grown plants, genotype SCA6 and cut perpendicular to the midvein into 2 pieces per leaf. The 2 pieces from each leaf where infected with the control and the treatment vectors individually, for total of 8 leaf pieces per vector. Prior to infection the cut surfaces of the mid-veins and secondary veins were sealed with melted paraffin (Paraplast Plus, McCormick Scientific). The sealed leaf pieces were submerged, abaxial side down, into $30 \mathrm{ml}$ bacteria solution with $0.02 \%$ Silwet L-77 (Vac-In-Stuff, added to the bacterial solution after induction) dispensed in Petri dishes (100 mm × 15 mm, VWR International, Radnor PA). The Petri dishes were placed in a $233 \mathrm{~mm}$ polycarbonate vacuum desiccator (Bel-Art, Wayne NJ) and vacuum pressure (22 psi) was applied for 2 min followed by a slow release. Leaves were then blotted dry on a paper towels and placed abaxial side up into a Petri dish $(100 \times 15 \mathrm{~mm})$ containing 6 layers of absorbent paper towels and one Whatman \#3 filter paper pre-moistened with $10 \mathrm{ml}$ sterile water. The Petri dishes were sealed with parafilm and incubated at $25^{\circ} \mathrm{C}$ for 2 days with light intensity of $145 \mathrm{~m}^{-2} \mathrm{sec}^{-1}$ and $14 \mathrm{~h}$ daylight. After two days, two replicate leaf pieces per vector were quickly frozen on liquid nitrogen. Total RNA was extracted as previously described [33] and cDNA was obtained as described above. The relative expression of TcNPR3 to TcActin was measured by RT-Q-PCR using Takara SYBR premix EX TaqII kit (Clontech) according to the user manual with 1:200 dilution of the cDNA template. For each measurement, two biological replicates, each with two technical replicates were performed for both genes using the primers described above.

Cacao pathogen Phytophthora capsici was activated on Petri dishes containing 10\% V8 medium (100 ml/l V8 juice, $3 \mathrm{~g} / \mathrm{l}$ calcium carbonate and $15 \mathrm{~g} / \mathrm{l}$ bacto agar) for two days at $27^{\circ} \mathrm{C}, 12 \mathrm{~h}$ daylight. Attached leaf pathogen bioassay was performed as previously described [23] on the remaining six leaf pieces. The right half of each leaf portion was inoculated with 3 agar plugs containing actively growing Phytophthora capsici mycelium and the left half was inoculated with sterile agar plugs as negative control. Inoculated leaves were incubated at $27^{\circ} \mathrm{C}$ and $12 \mathrm{~h}$ day/light cycle for three days before the evaluation of disease symptoms. Photographic images of the leaves were taken with a Nikon D90 camera and average lesion sizes were determined using ImageJ software tools (Imagej.nih. gov). Average lesion sizes are calculated from 18 measurements (6 leaf pieces, 3 replicates) and significance was determined by single factor ANOVA. To measure pathogen replication as a proxy of virulence, the ratio of Phytophthora DNA to cacao DNA was measured by RT-Q-PCR as follows. Tissue samples including the lesions $\left(1.4 \mathrm{~cm}^{2}\right.$ surrounding the inoculation site) were excised from the infected leaves and used for genomic DNA extraction using a Tissue Lyzer homogenizer and the DNeasy plant mini kit (Qiagen). The relative amount of Phytophthora capsici genomic DNA in leaf disks was measured by amplification of a PcActin gene (primer set F: GACAACGGCTCCGGTATGTGCAAGG and R: GTCAGCACACCACGCTTGGACTG) and TcActin7 (Tc01t010900) (primer set F: AGCTGAGAGATTCC GTTGTCCAGA and R: CCCACATCAACCAGACTT TGAGTTC) were used as pathogen and host targets respectively. DNA RT-Q-PCR was preformed as described in 
Wang et al. [48], using a ABI 7300 Real-Time PCR System (Penn State Genomics Core Facility), and the ratio of P. capsici DNA to cacao DNA in the infected tissues was calculated as two to the power of the difference between Ct numbers (2 $\left.2^{\text {(Ct-P. capsici - Ct-T.cacao) }}\right)$.

\section{Accession numbers}

Sequence data from this article can be found in the Arabidopsis Genome Initiative, GenBank databases or cacao genome browser (http://cocoagendb.cirad.fr/gbrowse/ cgi-bin/gbrowse/theobroma/) under the following accession numbers: At5g45110 (NPR3), At3g52590 (ubiquitin), BT031870.1(Phytophthora Actin), Tc06t011480/ JX983 187 (TcNPR3), Tc01t010900 (TcActin) and Tc06g000360 (TcTUB1).

\section{Results}

Isolation of a putative TCNPR3 gene

Initially, a partial TcNPR3 gene was identified by screening a BAC library by hybridization with a partial TcNPR1 sequence. Based on this sequence, PCR primers were used to amplify cDNA isolated from cacao genotype Scavina6 (SCA6) stage C leaves. A fragment of $1764 \mathrm{bp}$ was isolated, cloned into pGEM vector and sequenced to reveal an intact coding sequence of the expected length and with high homology to the Arabidopsis NPR3 gene.

Subsequently, a genomic sequence containing a putative TcNPR3 gene was identified by searching a cacao genome database (http://cocoagendb.cirad.fr/) [36] using the full-length cacao NPR3 cDNA as a query for the Blastn algorithm [38]. The structure of the TcNPR3 gene (Tc06t011480) was deduced by comparing the fulllength cDNA and genomic sequences using SPIDEY software tool (http://www.ncbi.nlm.nih.gov/spidey/index. html) [49], which revealed the presence of four exons and three introns, similar to the genomic structure of Arabidopsis NPR3 (Figure 1A).

\section{Arabidopsis and cacao NPR3 protein sequences are highly similar}

Conceptual translation of the TcNPR3 predicted transcript resulted in a putative protein sequence consisting of 587 amino acid residues, only one amino acid longer than Arabidopsis NPR3. Alignment of the TcNPR3 and AtNPR3 protein sequences demonstrated that they are highly similar to each other (60\% identity and $77 \%$ similarity). Arabidopsis and cacao NPR3 share key structural features (Figure 1B). Both proteins have a BTB/POZ domain near their $\mathrm{N}$-terminus (dashed line box) that shares 64\% identity and an ankyrin repeat region (solid line box) which shares about $72 \%$ identity. It has been shown that both $\mathrm{BTB} / \mathrm{POZ}$ domain and ankyrin repeats are involved in protein-protein interactions [50-53]. These similarities in protein structure suggested that TcNPR3 gene may also share the same function as AtNPR3 in the regulation of the defense response.
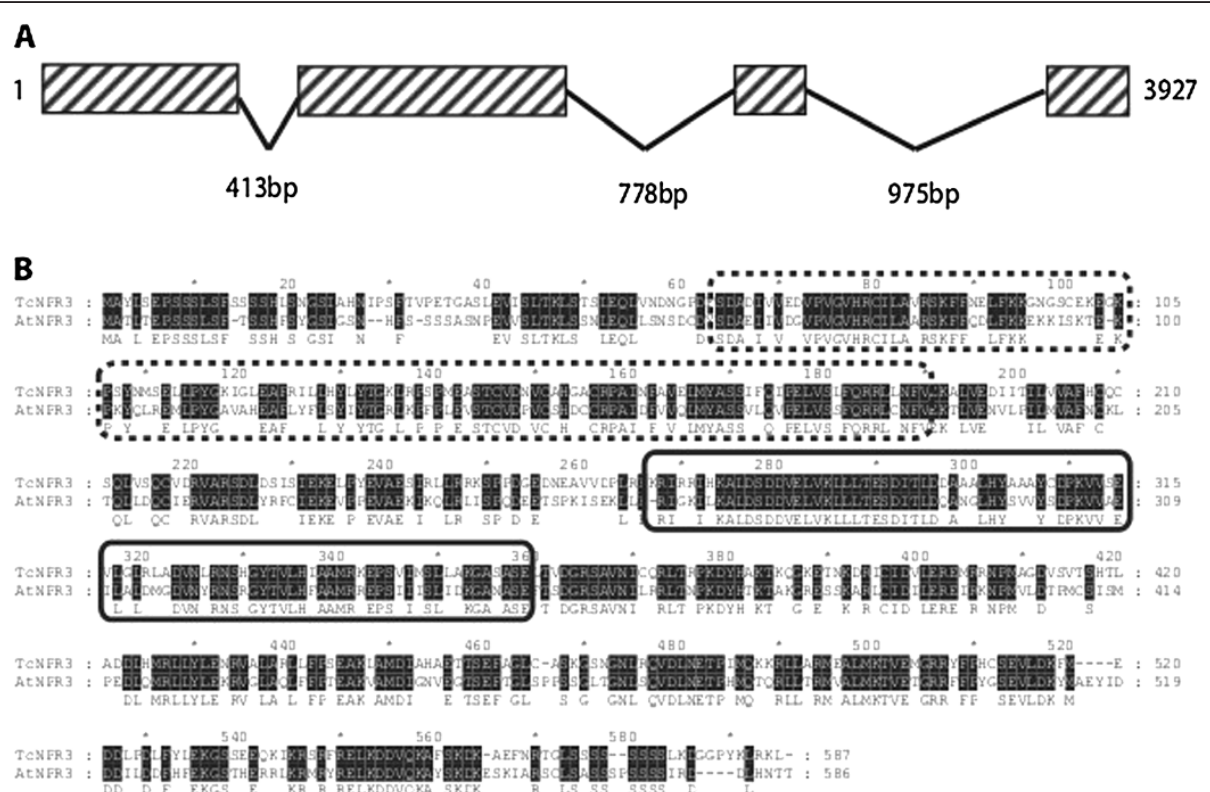

Figure 1 Gene and protein structure of Theobroma cacao NPR3. A. Diagram of the TCNPR3 gene structure. Boxes with diagonal stripes represent exons, slanted lines represent introns. The sizes of the entire genomic fragment and each intron are indicated. B. Alignment of the Arabidopsis NPR3 and predicted TCNPR3 proteins. Amino acids blocked in black indicate identical residues in both sequences and the amino acids below the blocks represent the consensus sequence. BTB/POZ and ankyrin repeat domains are highlighted by dashed lines and solid line boxes, respectively. 


\section{Expression of TCNPR3 in cacao tissues}

RT-Q-PCR was performed to investigate the expression level of TcNPR3 in various cacao tissues, including leaves from sequential developmental stages A, C, E, representing young, mid and mature stages of development. In addition, RNA was isolated from open flowers, unopened flowers, roots, seeds and fruit exocarp. TcNPR3 is constitutively expressed at varying levels, in all tissues tested (Figure 2), similar to the Arabidopsis NPR3 gene [23]. TcNPR3 basal expression levels were relatively low in seed and moderate in floral tissues and young and mid-development leaves (stage A and C). Its expression was high in roots, exocarps and mature leaves (stage E).

\section{TCNPR3 complements the Arabidopsis npr3-3 mutation}

Our earlier work has shown that the Arabidopsis npr3 mutant phenotype includes a enhanced level of floral disease resistance and significantly reduced whole plant fitness [23]. To explore the function of TcNPR3, we introduced the cacao NPR3 CDS under the control of a constitutive promoter into Arabidopsis npr3-3 mutant transgenic plants, and tested its ability to complement the npr3 mutant phenotype.

As compared to WT Arabidopsis, which is highly susceptible to Pseudomonas syringae pv. tomato DC3000 (P.s.t.), floral infection resulting in shortened siliques and reduced seed production, the primary phenotype of Arabidopsis npr3-3 mutant is normal silique and seed development regardless of the inoculation of pathogen [23]. To test if TcNPR3 overexpression in the npr3-3 mutant can complement this phenotype, the floral infection assay was carried out with five individual TcNPR3 transgenic lines, Col-0 and npr3-3 mutant Arabidopsis plants. We inoculated young developing flowers with P.s.t and disease symptoms and bacterial growth were assayed. In water-treated inflorescences, we did not observe any phenotypic differences in any of the different lines (Figure 3A). Seven days after inoculation, the P.s.t.-treated Col-0 plants were more susceptible than npr3-3 mutant plants, which showed impaired flower development and shorter siliques consistent with our previously reported results [23]. To evaluate the expression of the transgene, RT-PCR was performed using flowers of five independent transgenic lines along with wild-type Arabidopsis Col- 0 and the npr3-3 mutant controls. As expected, TcNPR3 expression was not detected in either Col-0 or the npr3-3 mutant, but five independent transgenic lines all showed heterologous expression of TcNPR3 (Figure 3C). All five individual transgenic lines exhibited intermediate levels of silique development after pathogen inoculation relative to Col-0 and npr3-3. To quantify these differences, the length of siliques of each infected inflorescence was measured in four biological replicates (Figure 3B). The mean silique length of the npr3-3 mutant was $11 \mathrm{~mm}$ regardless of the presence or absence of pathogen, but the silique length of infected Col-0 was significantly reduced to $1 \mathrm{~mm}$. All five independent transgenic npr3-3 lines overexpressing TcNPR3 exhibited intermediate silique lengths, ranging from $3 \mathrm{~mm}$ to about $8 \mathrm{~mm}$. The inoculated silique length of line 1 is statistically the same as Col- 0 , but all the other lines are significantly longer than Col-0 but shorter than in npr3-3 mutant plants.

To further evaluate the effect of the TcNPR3 transgene in the complementation lines, we quantified bacterial titers in infected floral extracts. A decrease of bacterial

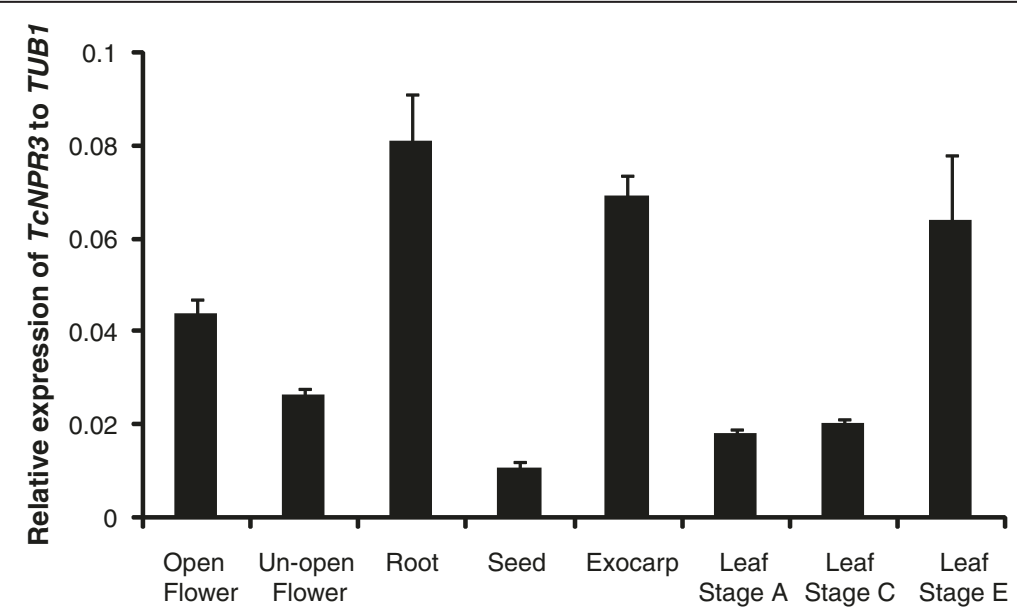

Figure 2 Gene expression analysis of TCNPR3 in various cacao tissues. Total RNA samples were collected from open flower, un-opened flower, root, seed, exocarp and three different leaf developmental stages from youngest to oldest (, , and $E$ ) with three biological replicates for each tissue. RT-Q-PCR was performed usingTCTUB1as a CDNA loading and normalization control. Expression levels are presented as the means \pm standard errors of three biological replicates. 


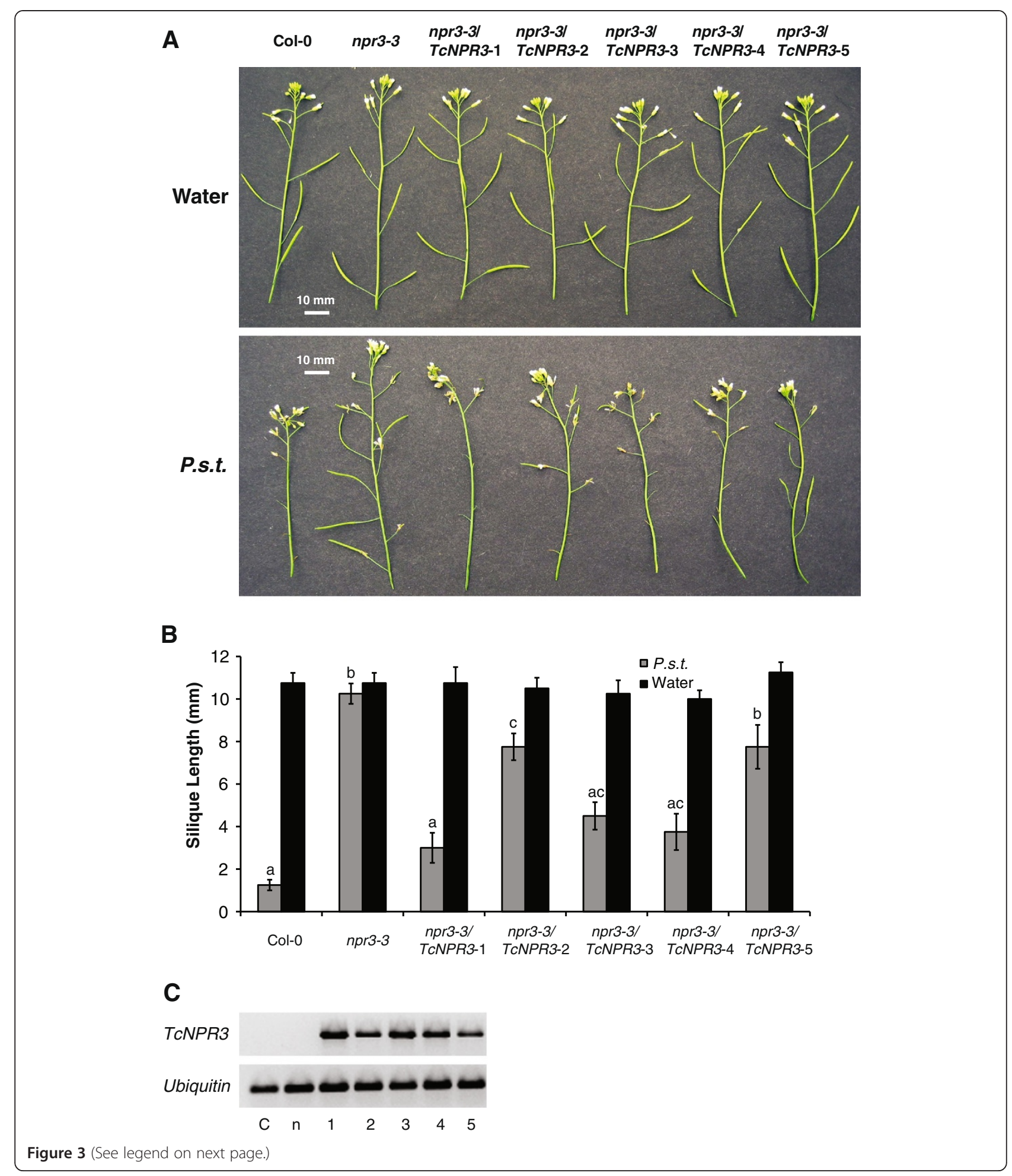


(See figure on previous page.)

Figure 3 Functional complementation of the Arabidopsis npr3-3 mutation by TcNPR3. Pseudomonas syringae pv. tomato DC3000 infection assay of transgenic npr3-3 mutant overexpressing TCNPR3. A. Representative images of siliques from infected Col-0, npr3-3 mutant and five independent lines of npr3-3 plants transformed with TCNPR3 seven days after inoculation with virulent bacteria Pseudomonas syringae pv. tomato DC3000 (P.s.t.) $\left(\mathrm{OD}_{600}=0.2\right.$ with $0.02 \%$ Silwet L-77) on top of the inflorescence. Additionally, water-treated (0.02\% Silwet L-77) inflorescences of seven genotypes served as mock inoculation. Size bars are indicated in white $(10 \mathrm{~mm})$. B. Average lengths of the fourth silique from the bottom of infected inflorescences seven days after inoculation (gray bars) compared to water mock inoculations (black bars). Bar chart represents means \pm SE of siliques from four biological replicates per treatment. Letters above the histogram indicate statistically significant differences among genotypes $(P<0.05)$ determined by single factor ANOVA. C. Gene expression of TCNPR3 in transgenic Arabidopsis npr3-3 lines. RT-PCR was performed with cDNA prepared from flowers of 6-week-old plants of wild type (C), npr3-3 mutant (n) and five individual transgenic npr3-3 mutant overexpressing TCNPR3 (1-5). Arabidopsis ubiquitin (AtUbiquitin) was assayed as an internal and cDNA loading control.

colonization of about 60-fold was observed in the npr3-3 mutant as compared to Col-0 (Figure 4). Although line 5 exhibited the same statistical level as npr3-3 mutant, two of the transgenic lines (Line 3 and 4) showed a level close to that of Col-0. The other two lines (line 1 and line 2) also supported significantly more bacteria than npr3-3 mutant though the level was not as high as in Col-0. In all, four out of five transgenic lines exhibited significantly higher bacteria levels than in npr3-3 mutant, again suggesting that TcNPR3 can at least partially complement npr3-3 mutant phenotype. The TcNPR3 protein only partially complemented the npr 3 mutant, most likely because of the heterologous nature of the interactions between TcNPR3 and the Arabidopsis defense response machinery. It is also possible that TcNPR3 has functions that differ from those of AtNPR3. To gain further evidence to support these conclusions, we tested TcNPR3 function directly in T. cacao, using a transient expression system.

\section{Knockdown of TCNPR3 in cacao leaves results in enhanced disease resistance}

Our expression data revealed that TcNPR3 is expressed at moderate to high levels in leaves depending on developmental stage (Figure 2). To test the function of TcNPR3 in cacao leaves, we knocked down its expression in cacao leaves by expressing an artificial microRNA via Agroinfiltration. We predicted that if NPR3 functions as a repressor of the NPR1-dependent defense response in cacao leaves, reduced NPR3 transcript would result in increased pathogen resistance proportional to the NPR3 expression level. To test this hypothesis, a $21 n t$ inverted repeathairpin construct was created based the design of Arabidopsis Mir319 [45] which was placed under control of an enhanced CaMV35S promoter. The artificial TcNPR3 microRNA construct was expressed in cacao leaves by Agrobacterium-mediated transient transformation via vacuum infiltration. Native NPR3 transcript levels were

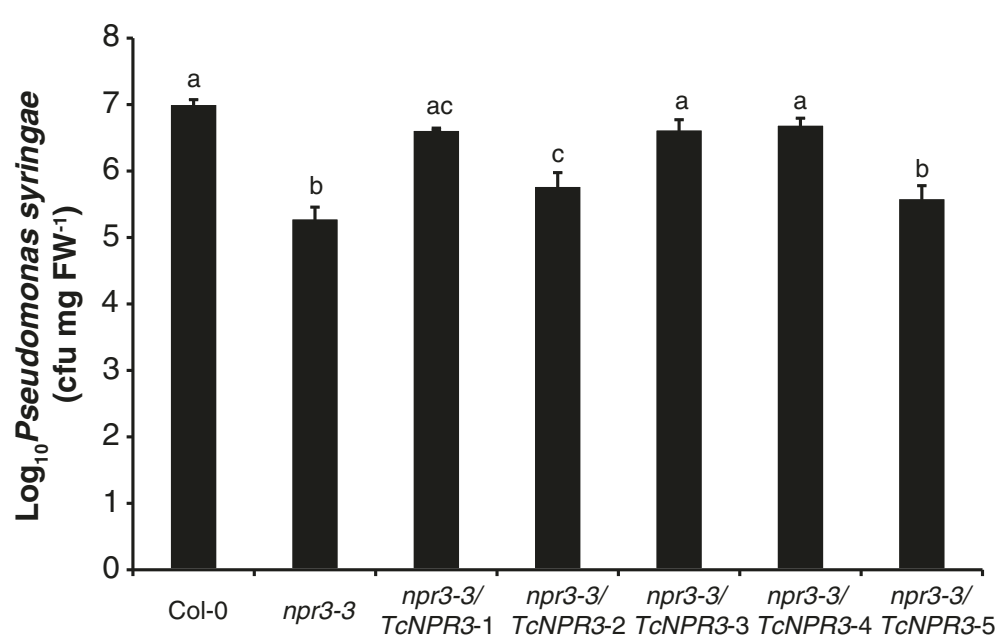

Figure 4 Functional complementation of the Arabidopsis npr3-3 mutation by TcNPR3. Bacterial populations of P.s.t. from infected flowers of Col-0, npr3-3 mutant and five individual transgenic lines. The whole inflorescences of six-week old plants (genotypes as indicated on $x$-axis) were inoculated with virulent P.s.t. DC3000 $\left(\mathrm{OD}_{600}=0.2\right.$ with $0.02 \%$ Silwet L-77) and bacterial growth was determined by bacterial titers five days after inoculation. Data represent means \pm SE of four replicates, each containing two infected inflorescences from two individual plants. Letters above the histogram indicate the statistical differences among different genotypes $(P<0.05)$ determined by Fisher's PLSD analysis. cfu, colony forming units. 
reduced up to $50 \%$ two days after transformation (Figure 5A). To explore the effect of NPR3 expression on the ability of cacao leaves to respond and defend against pathogen infection, we inoculated the leaves with the cacao pathogen Phytophthora capsici. Three days after infection, lesions were formed in both control and NPR3microRNA expressing leaf pieces (Figure 5B). Average lesion sizes were significantly reduced to about one-half those on controls (Figure $5 \mathrm{C}$ ). To test the ability of pathogen to replicate on the leaves, we quantified the ratio of Phytophthora to cacao genomic DNA in the infection zones by RT-Q-PCR or specific target genes, which further demonstrated that the TcNPR3-mircoRNA transgene significantly reduced pathogenicity (Figure 5D).

\section{Discussion}

The resources resulting from the complete genome sequence of Theobroma cacao were used to efficiently characterize the NPR1-like gene family of cacao [36]. We discovered a total of four NPR-like genes in the cacao genome. We previously reported that Tc09t007660 encodes TcNPR1, a functional ortholog of Arabidopsis NPR1 [35]. This report extends those findings to provide several lines of evidence supporting our hypothesis that Tc06t011480 (TcNPR3) encodes the functional ortholog of the Arabidopsis NPR3 gene. Two independent experiments testing TcNPR3 function were consistent with a role in suppression of the NPR1-dependent defense response pathway (Figures 3,4 and 5). The TcNPR3 gene complemented the npr3 mutant phenotype, which includes a dramatic increase in disease resistance. The fact that the complementation was only partial is not surprising, considering the large evolutionary distance of cacao and Arabidopsis. It is likely that specific protein-protein interactions between TcNPR3 and Arabidopsis components such as NPR1, or TGA2 might not be as strong as in homologous interactions, and thus we observed only partial complementation. However, our

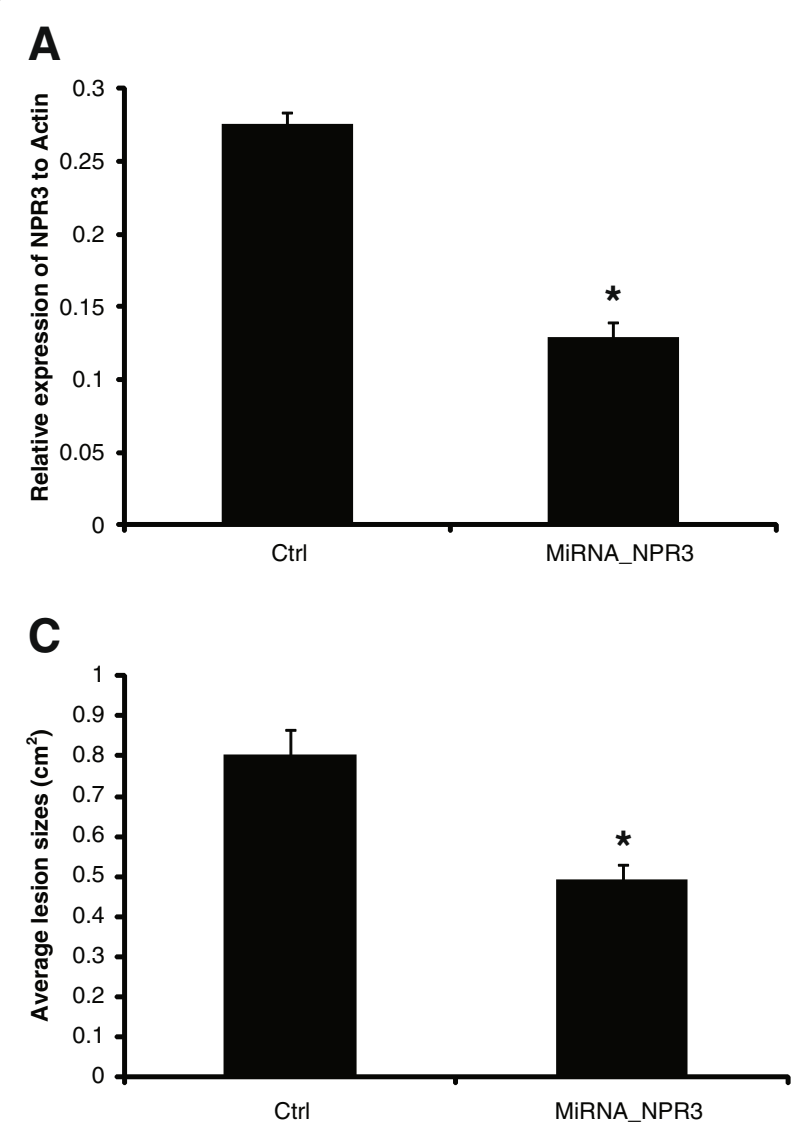

B
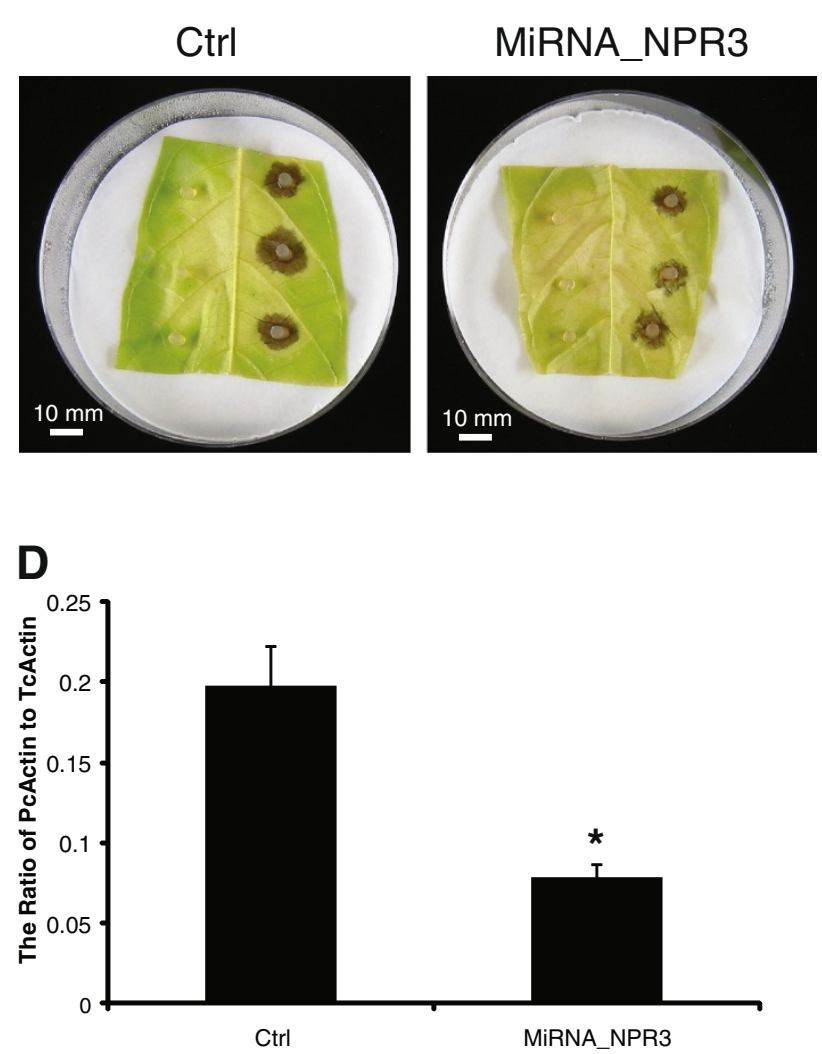

Figure 5 Pathogen bioassays of cacao leaves transiently transformed with a NPR3 microRNA. A. Relative expression of NPR3 in cacao leaves by RT-Q-PCR. RNA samples were collected two days after transformation by Agrobacterium vacuum infiltration. Genotypes are indicated on x-axis as: Ctrl: control vector. MiRNA-NPR3: micro RNA of cacao NPR3 derived from mir319a in Arabidopsis. B. Representative images of transformed leaves three days after inoculation with agar plugs containing Phytophthora capsici mycelium on the right and agar plugs with water on the left. Size bars are indicated in white $(10 \mathrm{~mm})$. C. Average lesion sizes (mean \pm SE of 12 lesion spots from four leaf discs). D. Relative virulence of $P$. capsici was measured by DNA RT-Q-PCR to calculate the ratio of pathogen actin to cacao actin three days after inoculation. Bars represent mean \pm SE of four biological replicates each with three technical replicates. Asterisks show statistically significant difference to Ctrl determined by ANOVA. 
data suggest that the mechanisms and molecules involved in NPR3-dependent signaling pathway in Arabidopsis are at least partially conserved with cacao. In a homologous test system, a cacao miRNA efficiently reduced endogenous TcNPR3 mRNA expression, and this in turn resulted in increased resistance to pathogen infection, consistent with the function of NPR3 as a repressor of the defense response.

The pathogen used in our experimental bioassays, $P$. capsici, is considered to be a hemibiotrophic pathogen, and causes significant losses worldwide [54-56]. Our unpublished data showed over-expression of cacao NPR1 gene can increase the resistance to $P$. capsici in detached leaf assays, which is consistent with previous findings that NPR1-dependent pathway is mainly involved in defense against (hemi) biotrophic pathogens.

In Arabidopsis, the npr 3 knockout mutant exhibits a high level of pathogen resistance in developing flowers compared to Col-0, WT plantlets [23]. This level of resistance is correlated with reduced seed number and weight, likely the result of a physiological cost of heightened defense activation. This clearly illustrates how the cost of resistance drives the selective pressure for evolution of complex and efficient negative regulatory mechanisms. We hypothesize that NPR3 plays a similar role in cacao. Cacao NPR3 gene expression is low in seeds, moderate in both floral tissues and young leaves, but elevated in the exocarps and stage E leaves (Figure 2). In contrast to the expression pattern or AtNPR3 in Arabidopsis, TcNPR3 only expressed at a moderate level in developing flowers, possibly because cacao is self-incompatible plant, so the tissue specificity might be different in this tropical tree. We speculate that evolution has selected for a mechanism that prioritizes resource allocation away from the mature exocarps and leaves, in favor of seeds, flowers and young leaves. This may play an important role for the pathogen Moniliopthora perniciosa, (witches' broom disease) which can infect developing flower cushions and cause hypertrophy and abnormal fruit development.

These findings could be used to guide the screening of cacao germplasm for novel sources of disease resistance that could be incorporated into breeding programs. Screening of cacao varieties for lines expressing low levels of NPR3 transcript could be a rapid method for discovery of potentially resistant varieties. By defining the specific genes and mechanisms involved in cacao disease resistance, and translating these discoveries into tools for germplasm screening and breeding, it will be possible to pyramid multiple genes for resistance into the elite cacao genotypes of the future.

\section{Conclusion}

The isolation of NPR3 from cacao and its heterologous complementation in Arabidopsis npr3 mutant allowed us to rapidly confirm its function in the negative regulation of defense response in floral tissues. Moreover, the knock down of TcNPR3 in cacao leaves via cacao transient transformation resulted in decreased resistance to cacao pathogen Phytophthora capsici in detached leaf bioassays. Taken together, we conclude that TcNPR3 is a functional ortholog of Arabidopsis NPR3 gene. This fundamental finding can potentially help us to breed cacao varieties with enhanced disease resistance by traditional breeding and/or transgenic manipulations, which will benefit farmers, developing countries, the environment and the chocolate industry.

\section{Competing interests}

No financial or non-financial competing interests exist related to the subject matter of this manuscript. No reimbursements, fees, funding, or salary were received from any organization that may in any way gain or lose financially from the publication of this manuscript, at any time. All costs of this research and its publication charges were funded by grants from the Penn State

Endowment in the Molecular Biology of Cacao. None of the authors hold stocks or shares in an organization that may in any way gain or lose financially from the publication of this manuscript, at any time. The authors are not currently applying for any patents relating to the content of the manuscript, nor have they received reimbursements, fees, funding, or salary from any organization that holds or has applied for patents relating to the content of the manuscript, There exist no non-financial competing interests (political, personal, religious, ideological, academic, intellectual, commercial or any other) to declare in relation to this manuscript.

\section{Authors' contributions}

ZS, SM and MG contributed to the design of all experiments, ZS was involved in implementation of most experimental plans and data acquisition, YZ contributed to the RT-Q-PCR experiment and data analysis of TCNPR3 expression across tissues, ZS and SM contributed to analysis and interpretation of all data as well as manuscript drafting and revision. MG conceived the overall plan of study, and participated in its design and coordination and helped to draft the manuscript. All authors read and approved the final manuscript.

\section{Acknowledgements}

We would like to thank Luis Mejia for providing help for the cacao pathogen bioassays. Thanks to members of the Guiltinan Lab, especially Joe Verica for performing the initial library hybridization screen for TCNPR3 and Siti Izzati Zulkafli and Lena Sheaffer for their technical assistance in the construction of cacao transformation vector and development of the cacao transient transformation method. This work is supported in part by The Pennsylvania State University, College of Agricultural Sciences, The Huck Institutes of Life Sciences, the American Research Institute Penn State Endowed Program in the Molecular Biology of Cacao and a grant from the National Science

Foundation BREAD program in cooperation with the Bill and Melinda Gates Foundation (NSF0965353).

\section{Author details}

${ }^{1}$ The Huck Institutes of the Life Sciences, The Pennsylvania State University, University Park, PA 16802, USA. ${ }^{2}$ The Department of Plant Science, The Pennsylvania State University, University Park, PA 16802, USA. ${ }^{3} 422$ Life Sciences Building, University Park, PA 16802, USA.

Received: 13 January 2013 Accepted: 27 November 2013

Published: 6 December 2013

\section{References}

1. Vlot AC, Klessig DF, Park SW: Systemic acquired resistance: the elusive signal(s). Curr Opin Plant Biol 2008, 11(4):436-442.

2. Heil M: Ecological costs of induced resistance. Curr Opin Plant Biol 2002, 5(4):345-350.

3. van Hulten M, Pelser M, van Loon LC, Pieterse CM, Ton J: Costs and benefits of priming for defense in Arabidopsis. Proc Natl Acad Sci USA 2006, 103(14):5602-5607. 
4. Koornneef $A$, Pieterse CM: Cross talk in defense signaling. Plant Physiol 2008, 146(3):839-844.

5. Glazebrook J: Genes controlling expression of defense responses in Arabidopsis-2001 status. Curr Opin Plant Biol 2001, 4(4):301-308.

6. Zhang S, Klessig DF: MAPK cascades in plant defense signaling. Trends Plant Sci 2001, 6(11):520-527.

7. Zhang HZ, Cai XZ: Nonexpressor of pathogenesis-related genes 1 (NPR1): a key node of plant disease resistance signalling network. Sheng Wu Gong Cheng Xue Bao 2005, 21(4):511-515.

8. Dong X: NPR1, all things considered. Curr Opin Plant Biol 2004, 7(5):547-552.

9. Cao H, Glazebrook J, Clarke JD, Volko S, Dong X: The Arabidopsis NPR1 gene that controls systemic acquired resistance encodes a novel protein containing ankyrin repeats. Cell 1997, 88(1):57-63.

10. McDowell JM, Cuzick A, Can C, Beynon J, Dangl JL, Holub EB: Downy mildew (Peronospora parasitica) resistance genes in Arabidopsis vary in functional requirements for NDR1, EDS1, NPR1 and salicylic acid accumulation. Plant J 2000, 22(6):523-529.

11. Nawrath C, Metraux JP: Salicylic acid induction-deficient mutants of Arabidopsis express PR-2 and PR-5 and accumulate high levels of camalexin after pathogen inoculation. Plant Cell 1999, 11(8):1393-1404

12. Zhang $Y$, Tessaro MJ, Lassner M, Li X: Knockout analysis of Arabidopsis transcription factors TGA2, TGA5, and TGA6 reveals their redundant and essential roles in systemic acquired resistance. Plant Cell 2003, 15(11):2647-2653.

13. Li X, Zhang Y, Clarke JD, Li Y, Dong X: Identification and cloning of a negative regulator of systemic acquired resistance, SNI1, through a screen for suppressors of npr1-1. Cell 1999, 98(3):329-339.

14. Zhang Y, Cheng YT, Qu N, Zhao Q, Bi D, Li X: Negative regulation of defense responses in Arabidopsis by two NPR1 paralogs. Plant J 2006 48(5):647-656

15. Journot-Catalino N, Somssich IE, Roby D, Kroj T: The transcription factors WRKY11 and WRKY17 act as negative regulators of basal resistance in Arabidopsis thaliana. Plant Cell 2006, 18(11):3289-3302.

16. Bowling SA, Guo A, Cao H, Gordon AS, Klessig DF, Dong X: A mutation in Arabidopsis that leads to constitutive expression of systemic acquired resistance. Plant Cell 1994, 6(12):1845-1857.

17. Weigel R, Bauscher C, Pfitzner A, Pfitzner U: NIMIN-1, NIMIN-2 and NIMIN-3, members of a novel family of proteins from Arabidopsis that interact with NPR1/NIM1, a key regulator of systemic acquired resistance in plants. Plant Mol Biol 2001, 46:143-160.

18. Weigel R, Pfitzner U, Gatz C: Interaction of NIMIN1 with NPR1 modulates PR gene expression in Arabidopsis. Plant Cell 2005, 17:1279-1291.

19. Durrant WE, Wang S, Dong X: Arabidopsis SNI1 and RAD51D regulate both gene transcription and DNA recombination during the defense response. Proc Natl Acad Sci USA 2007, 104(10):4223-4227.

20. Wu F, Zhang D, Chu J, Boyle P, Wang YC, Brindle I, De Luca V, Despres C: The Arabidopsis NPR1 protein is a receptor for the plant defense hormone salicylic acid. Cell Rep 2012, 1:639-647.

21. Canet JV, Dobon A, Roig A, Tornero P: Structure-function analysis of npr1 alleles in Arabidopsis reveals a role for its paralogs in the perception of salicylic acid. Plant Cell Environ 2010, 33(11):1911-1922.

22. Maier F, Zwicker S, Huckelhoven A, Meissner M, Funk J, Pfitzner AJP, Pfitzner UM: NONEXPRESSOR OF PATHOGENESIS-RELATED PROTEINS1 (NPR1) and some NPR1-related proteins are sensitive to salicylic acid. Mol Plant Pathol 2011, 12(1):73-91.

23. Mejia L, Guiltinan M, Shi Z, Landherr L, Maximova S: Expression of Designed Antimicrobial Peptides in Theobroma cacao L. Trees Reduces Leaf Necrosis Causedby Phytophthora spp. Small Wonders: Peptides for Disease Control 2012, 1095:379-395.

24. Fu ZQ, Yan S, Saleh A, Wang W, Ruble J, Oka N, Mohan R, Spoel SH, Tada $Y$, Zheng N, et al: NPR3 and NPR4 are receptors for the immune signal salicylic acid in plants. Nature 2012, 486(7402):228-232

25. Purdy LH, Schmidt RA: Status of cacao witches' broom: biology, epidemiology, and management. Annu Rev Phytopathol 1996, 34:573-594.

26. Meinhardt LW, Rincones J, Bailey BA, Aime MC, Griffith GW, Zhang D, Pereira GA: Moniliophthora perniciosa, the causal agent of witches' broom disease of cacao: what's new from this old foe? Mol Plant Pathol 2008, 9(5):577-588.
27. Andebrhan T, Maddison AC, Rudgard SA: International Office of Cocoa Chocolate and Sugar Confectionary: Disease management in cocoa: comparative epidemiology of witches' broom. London: Chapman \& Hall; 1993.

28. Mondego JM, Carazzolle MF, Costa GG, Formighieri EF, Parizzi LP, Rincones J, Cotomacci C, Carraro DM, Cunha AF, Carrer H, et al: A genome survey of Moniliophthora perniciosa gives new insights into witches' broom disease of cacao. BMC Genomics 2008, 9:548.

29. Lopes MA, Hora Junior BT, Dias CV, Santos GC, Gramacho KP, Cascardo JCM, Gesteira AS, Micheli F: Expression analysis of transcription factors from the interaction between cacao and Moniliophthora perniciosa (Tricholomataceae). Genet Mol Res 2010, 9(3):1279-1297.

30. Marelli J-P, Maximova S, Gramacho K, Kang S, Guiltinan M: Infection Biology of Moniliophthora perniciosa on Theobroma cacao and alternate Solanaceous hosts. Trop Plant Biol 2009, 2(3):149-160.

31. Tiburcio RA, Costa GG, Carazzolle MF, Mondego JM, Schuster SC, Carlson JE, Guiltinan MJ, Bailey BA, Mieczkowski P, Meinhardt LW, et al: Genes acquired by horizontal transfer are potentially involved in the evolution of phytopathogenicity in Moniliophthora perniciosa and Moniliophthora roreri, two of the major pathogens of cacao. J Mol Evol 2010, 70(1):85-97.

32. Gesteira AS, Micheli F, Carels N, Da Silva AC, Gramacho KP, Schuster I, Macedo JN, Pereira GAG, Cascardo JCM: Comparative analysis of expressed genes from cacao meristems infected by Moniliophthora perniciosa. Ann Bot 2007, 100(1):129-140.

33. Verica JA, Maximova SN, Strem MD, Carlson JE, Bailey BA, Guiltinan MJ: Isolation of ESTs from cacao (Theobroma cacao L.) leaves treated with inducers of the defense response. Plant Cell Rep 2004, 23(6):404-413.

34. Bailey BA, Strem MD, Bae H, de Mayolo GA, Guiltinan MJ: Gene expression in leaves of Theobroma cacao in response to mechanical wounding, ethylene, and/or methyl jasmonate. Plant Sci 2005, 168(5):1247-1258.

35. Shi Z, Maximova S, Lui Y, Verica J, Guiltinan M: Functional analysis of the Theobroma cacao NPR1 gene in Arabidopsis. BMC Plant Biol 2010, 10:248.

36. Argout X, Salse J, Aury JM, Guiltinan MJ, Droc G, Gouzy J, Allegre M, Chaparro C, Legavre T, Maximova SN, et al: The genome of Theobroma cacao. Nat Genet 2011, 43(2):101-108.

37. Argout X, Fouet O, Wincker P, Gramacho K, Legavre T, Sabau X, Risterucci AM, Da Silva C, Cascardo J, Allegre M, et al: Towards the understanding of the cocoa transcriptome: production and analysis of an exhaustive dataset of ESTs of Theobroma cacao L. generated from various tissues and under various conditions. BMC Genomics 2008, 9:512-531.

38. Altschul SF, Gish W, Miller W, Myers EW, Lipman DJ: Basic local alignment search tool. J Mol Biol 1990, 215(3):403-410.

39. Edgar RC: MUSCLE: multiple sequence alignment with high accuracy and high throughput. Nucleic Acids Res 2004, 32(5):1792-1797.

40. Mitsuhara I, Ugaki M, Hirochika H, Ohshima M, Murakami T, Gotoh Y, Katayose Y, Nakamura S, Honkura R, Nishimiya S, et al: Efficient promoter cassettes for enhanced expression of foreign genes in dicotyledonous and monocotyledonous plants. Plant Cell Physiol 1996, 37(1):49-59.

41. Hajdukiewicz P, Svab Z, Maliga P: The small, versatile pPZP family of Agrobacterium binary vectors for plant transformation. Plant Mol Biol 1994, 25(6):989-994.

42. Lin JJ: Electrotransformation of Agrobacterium. Methods Mol Biol 1995, 47:171-178

43. Clough SJ, Bent AF: Floral dip: a simplified method for Agrobacteriummediated transformation of Arabidopsis thaliana. Plant J 1998, 16(6):735-743.

44. Ossowski S, Schwab R, Weigel D: Gene silencing in plants using artificial microRNAs and other small RNAs. Plant J 2008, 53(4):674-690.

45. Schwab R, Ossowski S, Riester M, Warthmann N, Weigel D: Highly specific gene silencing by artificial microRNAs in Arabidopsis. Plant Cell 2006, 18(5):1121-1133.

46. Maximova S, Miller C, de Mayolo Antunez G, Pishak S, Young A, Guiltinan MJ: Stable transformation of Theobroma cacao $L$. and influence of matrix attachment regions on GFP expression. Plant Cell Rep 2003, 21(9):872-883.

47. Maximova SN, Marelli JP, Young A, Pishak S, Verica JA, Guiltinan MJ: Over-expression of a cacao class I chitinase gene in Theobroma cacao L. enhances resistance against the pathogen, Colletotrichum gloeosporioides. Planta 2006, 224(4):740-749.

48. Wang QQ, Han CZ, Ferreira AO, Yu XL, Ye WW, Tripathy S, Kale SD, Gu BA, Sheng YT, Sui $Y Y$, et al: Transcriptional programming and functional interactions within the Phytophthora sojae RXLR effector repertoire. Plant Cell 2011, 23(6):2064-2086. 
49. Wheelan SJ, Church DM, Ostell JM: Spidey: a tool for mRNA-to-genomic alignments. Genome Res 2001, 11(11):1952-1957.

50. Rochon A, Boyle P, Wignes T, Fobert PR, Despres C: The coactivator function of Arabidopsis NPR1 requires the core of its $\mathrm{BTB} / \mathrm{POZ}$ domain and the oxidation of C-terminal cysteines. Plant Cell 2006, 18(12):3670-3685.

51. Stogios PJ, Downs GS, Jauhal JJ, Nandra SK, Prive GG: Sequence and structural analysis of BTB domain proteins. Genome Biol 2005, 6(10):R82.

52. Li J, Mahajan A, Tsai MD: Ankyrin repeat: a unique motif mediating protein-protein interactions. Biochemistry 2006, 45(51):15168-15178.

53. Albagli O, Dhordain P, Deweindt C, Lecocq G, Leprince D: The BTB/POZ domain: a new protein-protein interaction motif common to DNA- and actin-binding proteins. Cell Growth Differ 1995, 6(9):1193-1198.

54. Gobena D, Roig J, Galmarini C, Hulvey J, Lamour K: Genetic diversity of Phytophthora capsici isolates from pepper and pumpkin in Argentina. Mycologia 2012, 104(1):102-107.

55. Lamour KH, Mudge J, Gobena D, Hurtado-Gonzales OP, Schmutz J, Kuo A, Miller NA, Rice BJ, Raffaele S, Cano LM, et al: Genome sequencing and mapping reveal loss of heterozygosity as a mechanism for rapid adaptation in the vegetable pathogen Phytophthora capsici. Mol Plant Microbe Interact 2012, 25(10):1350-1360.

56. Lamour KH, Stam R, Jupe J, Huitema E: The oomycete broad-host-range pathogen Phytophthora capsici. Mol Plant Pathol 2012, 13(4):329-337.

doi:10.1186/1471-2229-13-204

Cite this article as: Shi et al:: TcNPR3 from Theobroma cacao functions as a repressor of the pathogen defense response. BMC Plant Biology 2013 13:204.

\section{Submit your next manuscript to BioMed Central and take full advantage of:}

- Convenient online submission

- Thorough peer review

- No space constraints or color figure charges

- Immediate publication on acceptance

- Inclusion in PubMed, CAS, Scopus and Google Scholar

- Research which is freely available for redistribution 